\title{
A EDUCAÇÃO AMBIENTAL A PARTIR DAS CONCEPÇÕES DE NATUREZA E DE TRABALHO DE PESCADORES
}

\author{
ENVIRONMENTAL EDUCATION FROM THE FISHERMEN'S CONCEPTIONS OF NATURE \\ AND WORK
}

\author{
EDUCACIÓN AMBIENTAL DESDE LAS CONCEPCIONES DE NATURALEZA Y DE \\ TRABAJO DE LOS PESCADORES
}

\author{
Maicon Dourado Bravo \\ (SEEduc/RS, Brasil) \\ José Vicente de Freitas \\ (FURG, Brasil)
}

https://doi.org/10.29404/rtps-v5i8.199

\begin{abstract}
RESUMO: 0 artigo reflete sobre a concepção que os pescadores artesanais do estuário da Lagoa dos Patos têm acerca de natureza e de trabalho, conceitos com os quais a Educação Ambiental pode trabalhar para construir formas de produção e reprodução da vida socialmente justa e ambientalmente sustentável como alternativas à sociedade capitalista industrial moderna. A relação que se estabelece com a natureza, caracterizada pela harmonia e luta dos pescadores, de forma a constituir uma prática profissional que é marcada pelo caráter polivalente, diverso, comunitário e satisfatório entre os pescadores artesanais, serve de subsídio para a Educação Ambiental na organização de sua práxis. Os depoimentos dos pescadores foram obtidos por meio do método da História Oral. Importa à Educação Ambiental, para potencializar seu caráter crítico, transformador e emancipatório, aproximar-se dos grupos e comunidades tradicionais e construir junto a eles sua práxis.
\end{abstract}

Palavras-chave: Trabalho, Pesca, Conservação da natureza, Trabalho e educação, Educação Ambiental.

ABSTRACT: The article reflects about the Lagoa dos Patos estuary artisanal fishermen's conception of the regarding nature and labour, concepts with which Environmental Education can work to build socially just and environmentally sustainable forms of production and reproduction of life, like alternatives to modern industrial capitalist society. The relationship established with nature, characterized by the harmony and struggle of fishermen, in order to constitute a professional practice that is marked by the multipurpose, diverse, community and satisfactory nature among artisanal fishers, serves as a subsidy for Environmental Education in the organization of its praxis. The fishermen statements were obtained using the Oral History method. It is important for the Environmental Education, in order to enhance its critical, transformative and emancipatory character, to approach the traditional groups and communities and to build its praxis with them.

Keywords:, Work, Fishing, Nature Conservation, Work and Education, Environmental Education.
RESUMEN: El artículo reflexiona sobre la concepción que los pescadores artesanales del estuario Lagoa dos Patos tienen sobre la naturaleza y el trabajo, conceptos con los que la Educación Ambiental puede trabajar para construir formas de producción y reproducción de vida socialmente justa y ambientalmente sostenible como alternativas. a la moderna sociedad capitalista industrial. La relación establecida con la naturaleza, caracterizada por la armonía y la lucha de los pescadores, a fin de constituir una práctica profesional marcada por el carácter versátil, diverso, comunitario y satisfactorio entre los pescadores artesanales, sirve como subsidio para la Educación Ambiental en la organización. de tu praxis Los testimonios de los pescadores se obtuvieron utilizando el método de Historia Oral. La educación ambiental es importante, para mejorar su carácter crítico, transformador y emancipador, para acercarse a los grupos y comunidades tradicionales y construir su praxis con ellos.

Palabras clave: Trabajo, Pesca, Conservación de La Naturaleza, Trabajo y Educación, Educación Ambiental. 


\title{
Considerações iniciais
}

A relação dialética existente entre a natureza e o trabalho se configura como a relação ontológica da humanização do ser humano, como traço distinto da formação da espécie, e representa a formação e a transformação da própria natureza para a humanidade. Tanto que Marx aponta a inter-relação entre natureza e trabalho escrevendo na "Crítica ao Programa de Gotha":

O trabalho não é a fonte de toda riqueza. A natureza é a fonte dos valores de uso (e é em tais valores que consiste propriamente na riqueza material!), tanto quanto o é o trabalho, que é apenas a exteriorização de uma força natural, da força de trabalho humana (MARX, 2012, p. 23).

Corrobora esta posição o início do texto de Engels, "Humanização do macaco pelo trabalho", com a seguinte afirmação:

\begin{abstract}
O trabalho é a fonte de toda riqueza, afirmam os economistas. E o é, de fato, ao lado da natureza, que lhe fornece a matéria por ele transformada em riqueza. Mas é infinitamente mais do que isso. É a condição fundamental de toda a vida humana; e o é num grau tão elevado que, num certo sentido, pode-se dizer: o trabalho, por si mesmo, criou o homem (ENGELS, 1979, p. 215).
\end{abstract}

Elemento que atribui sentido à existência humana, ele distingue, através da forma pela qual é organizado, os diferentes ofícios humanos, seja o pescador artesanal ou o embarcado, o operário do estaleiro ou da indústria de fertilizantes, muito embora estes três últimos tenham passado por um processo intensivo de proletarização que opera uma disjunção do trabalho e dos meios de realizá-lo.

Este artigo se propõe a realizar uma breve reflexão a respeito das concepções de natureza e trabalho presentes entre os pescadores artesanais e as ameaças presentes na sociedade capitalista industrial moderna a este modo de organização da produção e de relação com o meio, abalados irremediavelmente desde a década de 1970 com a implementação da Lei da Pesca, inserindo a Lagoa dos Patos na conjuntura de crise estrutural do capitalismo. Busca-se compreender a magnitude dos impactos que foram desferidos sobre a lagoa como resultados da ideologia do progresso aplicados à economia regional e as formas pelas quais é possível organizar a superação deste estado de crise.

Este texto compõe tese produzida dentro do Programa de Pós-Graduação em Educação Ambiental (PPGEA-FURG), e traz depoimentos dos pescadores artesanais entrevistados durante a elaboração da pesquisa. O método da História Oral foi fundamental para o registro das histórias de vida de pescadores e pescadoras, considerando a necessidade de compreender a construção da categoria pescador artesanal a partir de sua própria subjetividade. Os depoimentos, que foram orientados pelo pesquisador a percorrer um itinerário que contemplasse pontos-chave como a infância entre a pesca, a iniciação na pesca, a profissionalização e estado atual da pesca no estuário, foram o material com o qual se conseguiu construir as reflexões presentes neste artigo. 


\section{Natureza na pesca}

A concepção de natureza dentro da perspectiva teórica utilizada neste artigo, tomada como corpo inorgânico do ser humano, com o qual ele deve estabelecer um processo contínuo para não morrer, sendo parte da própria natureza, se embasa em seu caráter ontológico e formativo da realidade existente, originário, anterior e independente do pensamento. Nesta concepção materialista da natureza, qualquer transformação operada por meio da atividade humana resulta, simultaneamente, em transformações no próprio ser humano. O simples fato de hoje a pesca artesanal se encontrar ameaçada e depauperada são provas da validade desta concepção, resultado da ação humana no meio para se atingir determinados fins que acabam por impactar de forma integral toda a natureza.

O grupo de pescadores artesanais se constitui em uma categoria profissional de particular interesse para a realização de estudos no sentido de perceber a relação dialética entre natureza-ser humano, dada sua proximidade teórica e prática com a natureza. A relação estabelecida pelos pescadores artesanais se caracteriza por um duplo movimento, baseado tanto pela harmonia quanto pela luta pela sobrevivência (FOSTER, 2011, p. 287).

Este processo contínuo estabelecido pelos pescadores com a natureza é típico da relação da humanidade, enquanto gênero, com a natureza. Sua desconexão é impossível sem efeitos irremediavelmente negativos para o ser humano, o que acaba por afirmar, em última instância, que ser humano e natureza coincidem. E isto é de fundamental importância para a Educação Ambiental pois

\footnotetext{
[...] A natureza é vista não somente como fonte de recursos, mas como ontologicamente prioritária para a existência humana, aquilo que nos antecede e que de nós independe, cuja dinâmica ecológica, mesmo que por nós mediada e transformada, precisa ser conhecida e respeitada a fim de que o modo de produção seja compatível com sua capacidade de suporte e de regeneração (LOUREIRO, 2012a, p. 29).
}

Acredita-se que a concepção de natureza construída pelos pescadores artesanais tenha o potencial de fomentar o conhecimento e o respeito aos ciclos da natureza, com vistas a fundamentar a construção de um modo de produção compatível com seus próprios ritmos naturais.

\section{A relação com a natureza enquanto harmonia}

A relação que os pescadores estabelecem com a natureza tem um caráter harmônico evidenciado pela compreensão dos ciclos naturais por parte destes pescadores, e estes ciclos integram necessariamente a vida do grupo. Em pesquisa anterior, se pôde verificar a existência dessa compreensão e da histórica adaptação aos ritmos naturais da lagoa, seja pela observação do comportamento dos cardumes, identificação de seus hábitos e seus ciclos de entrada, reprodução e saída da lagoa. O grau de intimidade que as comunidades pesqueiras estabeleceram com o estuário revela, ante de tudo, uma profunda sintonia com 
a natureza na qual estavam inseridos, evidência do caráter harmônico em sua relação com o meio.

A compreensão dos ritmos naturais extravasa o estuário e se estende à ação de outros sujeitos e grupos no trato com a lagoa e suas adjacências, o que permite a Mané, pescador que atua no estuário há algumas décadas, compreender o caso da lama na Praia do Cassino (GAÚCHAZH, 2018) de modo diverso ao que se tem veiculado nos meios de comunicação e nos debates acadêmicos a respeito do tema.

[...] Eu digo: "Pois é. E aí, sabe aqueles esqueminha que dá no Cassino que eles dizem que não é, é a natureza, que isso aí é coisa da natureza. Da natureza nada, cara. Aquilo ali é o que tiram de dentro do porto e largam lá no meio do oceano e o Cassino, como é que é a Praia do Cassino? A Praia do Cassino é de carinha, de frente pro Sul, é o vento que mais dá pra nós aqui, é Sul. Joga tudo pra praia. Vê se na Praia do Norte dá... Não passa, a Praia do Norte é ao correr, ao correr".

O entendimento da dinâmica das marés, dos ventos e dos cardumes aproxima os pescadores artesanais de uma visão integrada de sua existência enquanto grupo de uma natureza necessariamente saudável para que possam se realizar enquanto sujeitos e grupos. A limitação técnica, ao invés de um obstáculo que se interpõe para a interpretação dos sinais da natureza, serviu como um reforço para que se construísse uma forma de compreendê-la sem a intermediação de aparatos tecnológicos. A fluidez das águas, a força dos ventos, a chuva e a seca são sinais que os pescadores utilizam para traçar seus planos e projetos, para prever uma safra boa ou uma safra ruim. Seu Lica, velho pescador que passou uma vida toda dedicado à atividade na lagoa, vitimado por uma cobra cruzeira, foi testemunha do tempo em que a escassez de recursos permitiu que se entendesse o estuário de forma ampla e harmônica.

[...] de primeiro nós não usava nada de sonda, nada de... assim, de primeiro era... quem fumava, o único fogo que o cara usava era o dos fósforos que acendiam o cigarro, ou faziam o cigarro, porque quem não fumava não usava. Não usava uma lanterna, não usava nada e saía mar afora, só céu e mar. A bússola do cara era sol... e de noite a lua ou as estrela, então por isso aí... Que o cara saía aí pra fora, tinha um certo ponto que tu só via mar e céu, mais nada.

Para além dessa compreensão ampla da natureza da lagoa, existe também a admiração e o respeito evocados pelo contato em proximidade com o estuário. Mariza, filha de pescadores, pescadora, e liderança comunitária, aponta a natureza idílica dessa relação quando diz:

[...] A gente que vive na área da pesca sente uma necessidade de levantar e olhar pro mar, e olhar pra lagoa, porque para nós aqui o mar é a lagoa. [...] Acabei casando com um rapaz que não vivia da pesca..., mas acho que pelo amor que a gente tinha pela pesca, ele acabou virando pescador.

A compreensão íntima dos ciclos e ritmos da lagoa e a admiração que ela desperta convergem para a concepção do caráter harmônico da relação dos pescadores com a natureza. Relação de interdependência, em que uma lagoa rica significa pujança na pescaria, e o ataque indiscriminado aos cardumes resulta em períodos de privação, evocando a necessidade de um equilíbrio na forma pela qual a pesca se realiza. 
Mais do que espaço de trabalho e moradia, a lagoa, delimitação local da natureza com a qual o grupo de pescadores artesanais estabelece relações de produção e reprodução física e espiritual, é uma determinação que constitui sua subjetividade. Tratando das características do que convencionou chamar de aura, ligada à relação que os sujeitos estabelecem com as coisas e com o ambiente que os rodeia, Walter Benjamin aponta que:

\footnotetext{
Se chamamos de aura às imagens que, sediadas na mémoire involuntaire, tendem a se agrupar em torno de um objeto de percepção, então esta aura em torno do objeto corresponde à própria experiência que se cristaliza em um objeto de uso sob a forma de exercício (BENJAMIN, 1994, p. 137).
}

Os apetrechos de pesca estão todos impregnados com esta aura constituída na relação com a natureza. A compreensão mesma da impossibilidade de existência do ser humano sem uma natureza saudável se efetiva na declarada necessidade de Mariza estabelecer uma sintonia entre seu ser e o ambiente que a cerca.

Tomada, em poucas palavras, como a vivência individual matizada pelos tons do trabalho, a experiência é cristalizada nos objetos de trabalho utilizados na relação com a lagoa, tal qual as redes de seu Lica, que datam de tempos além da lembrança e que continuavam sendo usadas e remendadas até pouco antes de sua morte. Não o objeto em si, mas o objeto impregnado de trabalho é que remete à memória da lagoa. A permanência da natureza na vida dos pescadores é um traço necessário para a construção da categoria pescador artesanal, dando sentido prático a Marx, quando este diz que "o trabalho nada pode criar sem a natureza, sem o mundo exterior sensível. Ela é a matéria na qual o seu trabalho se efetiva, na qual [o trabalho] é ativo, [e] a partir da qual e por meio da qual [o trabalho] produz" (MARX, 2010, p. 81).

Estabelece-se um laço de dependência do pescador em relação à lagoa, ao mesmo tempo em que esta é constantemente alterada por aquele. Esta mútua transformação, influenciada pelas interferências da produção capitalista, legou à memória de seu Lica a fartura de uma relação harmônica com a natureza, quando foi relatada a quantidade de pescado abatido em tempos de limitação técnica. "[...] Dava dois, três lance, e vinha embora pra terra. Matava quatrocentos, quinhentos, mil quilos num lance só, de bagre, corvina. Dava, naquela época, muita quantidade de bagre, corvina, barbaridade, matava corvina".

A relação dialética entre os seres humanos e a natureza na sociedade capitalista industrial moderna, desprovida em grande parte do caráter harmônico presente entre os pescadores artesanais, colocou, sob a ideologia do progresso, os ritmos da natureza submetidos aos ritmos do relógio e da lucratividade. O trabalho e a subsistência dos pescadores ficam comprometidos, pois a sobreposição de formas de se relacionar com a natureza consideradas harmônicas por outras formas que aceitam a disjunção ser humano/natureza coloca em xeque a sustentabilidade das atividades humanas a médio e longo prazo.

A ideia de dominação da natureza, como vista na sociedade capitalista, não se encontra presente entre os pescadores artesanais. Prestando legitimidade às palavras de Loureiro, a razão dos pescadores identifica uma interação com a natureza e na natureza 
(LOUREIRO, 2012b. p. 25), e esta razão não se constitui de forma efêmera ou abstrata, mas de modo integrado à materialidade, levando em conta os intransponíveis limites da natureza para o desenvolvimento econômico infinito apregoado pela lógica capitalista.

Assim, Diegues (2008, p. 66) propõe que:

[...] Não é simplesmente a natureza, as limitações geográfico-ambientais que motivam um tipo específico de exploração dos recursos naturais [...], mas sim as formas com que se configuram as relações sociais, suas racionalidades intencionais, seus objetivos de produção material e social.

Dito isso, a postura dos pescadores artesanais diante da natureza enquanto harmoniosa em suas relações não se dá de forma fortuita ou acidental, e não é produto do baixo desenvolvimento técnico, mas justamente seu causador: a relação dos pescadores artesanais com a natureza apresenta um caráter harmônico por este grupo compreenderse como parte da natureza, dotada de uma dinâmica que se contrapõe em certa medida à cisão presente na sociedade capitalista.

Obviamente não é possível transformar o grupo dos pescadores artesanais do estuário da Lagoa dos Patos nos guardiões absolutos das boas relações com a natureza. Por estarem em contato diuturno com os mecanismos e dispositivos da sociedade capitalista, sempre acaba por haver influências, sentidas prioritariamente pelo campo não-hegemônico desta relação. Os valores e a razão capitalista acabam penetrando o grupo de pescadores, fomentando a sua adoção. No entanto, por uma operação de exclusão de aspectos semelhantes, se percebe que o trato do pescador com a lagoa leva em consideração uma forma de relacionar-se que não parte do domínio da natureza. Toco, pescador que se iniciou na pesca artesanal, mas em pouco tempo empregou-se como operário, ilustra este pensamento:

[...] Eu sou um pescador que sempre pensei numa coisa só: não em quantidade, e sim qualidade. Se todo pescador fosse, há muitos anos atrás, pensando isso aí sempre, venderia o melhor produto, por isso que o produto hoje, as empresas caíram e virou só o atravessador.

[...] Então se todo pescador pensasse na qualidade e não na quantidade, talvez até hoje teria pegando um preço melhor e as empresas tivessem se mantido mais. Mas eles pensavam muito em quantidade, como a de arrasto também, é quantidade, aí tu chega ali e tu vende o teu pescado, trinta por cento do teu pescado era aproveitável, o restante vai pra farinha. Isso eu tô falando sobre o arrasto lá de fora, é pra farinha, e o resto é descartável.

A diferenciação que Toco faz a respeito das grandezas priorizadas pelos pescadores traz consigo a compreensão da inseparabilidade de seres humanos e natureza, e do caráter dialético da relação estabelecida entre os dois. Ao dedicar-se à "qualidade" do pescado, Toco demonstra que o incremento para ampliar a "quantidade", embasado por uma racionalidade imediatista e exclusivamente abstrata resultará necessariamente em profundos impactos para a pesca na lagoa. Emerge o entendimento de que a reprodução social dos pescadores artesanais está imediatamente ligada à reprodução da natureza (DIEGUES, 1983, p. 95).

O caráter harmônico da relação dos pescadores com a natureza emerge, portanto, pela compreensão integral de pertencimento à própria natureza, esta enquanto elemento 
constitutivo da subjetividade do grupo, que inspira, fundamenta e dá sentido à sua prática, e da interconexão entre a saúde da prática pesqueira e da própria natureza, destacando uma racionalidade diversa da razão hegemônica na sociedade capitalista industrial moderna, que prioriza o aspecto qualitativo da produção.

\section{A relação com a natureza enquanto luta}

A relação harmônica dos pescadores artesanais com a natureza é complementada por uma relação conflituosa, uma luta literal por sobrevivência, pois a natureza, o mar, representa por vezes uma séria ameaça que lhes exige prudência e bom senso no trato, particularmente nas pescarias que se davam ou se dão no oceano. A atenção aos sinais da natureza e às mudanças no clima são fundamentais para sobreviver à intempérie, característica que por vezes os mais jovens ainda não adquiriram, como aponta seu Lica:

\footnotetext{
Porque tinha uns que eram mais teimosos, então não cuidavam muito o tempo, aquela coisa. Nós, por exemplo, cuidava, porque nós só ia em calma de rebojo, vento sul: dava aquele vento sul, dois, três dias, na calma a gente ia, a gente saía. Saía na calma, dava um, dois dias de monção, aí quando o tempo começava a ficar ruim, a gente parava. Isso é assim...
}

Aí começou esses mais novo a sair e querer enfrentar o tempo... Uma embarcaçãozinha daquelas pequena não tem condições de encostar aí no oceano.

Percebe-se, pela fala de seu Lica, que a opção de enfrentar o mar raramente se caracterizava como uma opção de sucesso. O respeito e mesmo o temor às forças da natureza constituem um traço distintivo, seja no trato direto com a lagoa, seja em suas vivências cotidianas, quando uma tempestade poderia arruinar as embarcações.

Do mesmo modo que seu Lica recomenda a prudência, Mariza também destaca o temor que o mar inspira e as tragédias vivenciadas nas comunidades pesqueiras quando relata que:

[... por] um bom tempo os pescadores artesanais iam pescar lá no oceano, e isso me dava medo, muito medo, porque as embarcações do pescador são pequenas. Quando dá aqueles temporais que pega de repente, que eles dizem que fecha a Boca da Barra, e aí como é que fica? Quantos acidentes se ouviu falar, de se perder vidas. Isso dava medo porque eles iam pescar o peixe de fundo e a corvina, no início.

A Boca da Barra, o ponto de comunicação entre a Lagoa dos Patos e o oceano, representa, no depoimento de Mariza, a barreira limítrofe entre o "dentro" e o "fora", entre a relativa segurança da lagoa e a intempérie absoluta para os pescadores artesanais e seu baixo desenvolvimento técnico. No entanto, o caráter de luta da relação dos pescadores com a natureza não se resume à luta pela sobrevivência em caso de tempestades e acidentes climáticos, mas também na luta pela obtenção do pescado, na atividade produtiva e seus resultados.

Dado que a relação estabelecida é marcada pela transformação que o ser humano opera na natureza, o caráter de luta emerge da interpenetração entre natureza e sociedade, em que se torna possível, por meio da compreensão da dinâmica natural, intervir com 
possibilidade de obtenção de melhores resultados das andainas no canal, cravadas para disposição das redes de forma a interceptar os cardumes em curso. Se a natureza é o "[...] pressuposto por excelência para qualquer processo produtivo humano, e, portanto, para o próprio desenrolar da história" (DUARTE, 1995, p. 67), também é verdade que, por mais dadivosa que a lagoa possa ser, já ter sido, ou voltar a ser, a realização da pesca se dá numa relação de enfrentamento do pescador com a natureza. Destaca-se, porém, que esse enfrentamento não implica o domínio sobre a natureza, pois o caráter harmônico sempre lembrará o pescador que a destruição da lagoa é equivalente à sua própria destruição.

Todos os instrumentos de pesca, ao mesmo tempo em que trazem inscritos neles a aura formada na relação com a lagoa, são os meios pelos quais os pescadores transformam seu meio, e nessa luta eles constroem sua relação histórica com a natureza: "[...] A natureza assim assume significado prático para a humanidade como o resultado da atividade de vida, a produção do meio de vida" (FOSTER, 2011, p. 107). A lagoa se torna parte da vida das comunidades pesqueiras justamente na aquisição de sentido que se dá no embate pela subsistência, no confronto ao qual estão expostos os pescadores na realização de suas vidas. E, não sendo poucas as agruras que existem na relação de luta com a natureza, evidenciadas por Mané quando diz que "[...] a profissão do pescador, ela é ralada, ela judia, ela é muito, muito perigosa" destacando que já havia perdido um tio e um amigo na lagoa com um "rebojinho", os pescadores artesanais seguem em sua realização profissional tradicional, tendo de disputar os sentidos sobre a lagoa com outros grupos.

A luta com a natureza, hoje, é uma luta por uma natureza que vem sendo sobreexplorada. Envolve não só o embate com a natureza, mas de certo modo um embate pela natureza, na medida em que interesses diversos se fazem sentir sobre a lagoa e lhe dão diferentes usos, vários deles excludentes para os pescadores.

Seu Lica avalia a condição desta luta quando dizia que: Hoje em dia a pescaria tá difícil, principalmente pra trabalhar de proeiro, porque não tem
quase pescaria, esses barcos acabam com tudo aí na volta do oceano, não tem como. Tem
caras que não notam isso, mas o cara nota que falta. Ainda agora quando mexeram com esse
molhe, que aumentaram mais lá, ficou mais difícil. Aquele caminho dos peixes fica diferente.

O impacto e a sobre-exploração se dão pela conjunção de fatores como a pesca de arrasto oceânica, o desenvolvimento do porto de Rio Grande, as indústrias instaladas na Barra e com os arrozeiros que despejam águas represadas na lagoa (XXX, 2011, p. 72). E este traço serve para compreender que o duplo caráter da relação dos pescadores artesanais com a natureza, relação histórica, não se dá através de uma abstração ou de forma efêmera, mas é construída cotidianamente através de sua experiência de vida e de trabalho na materialidade, na concretude. A relação harmônica e de luta dos pescadores com a lagoa é produto de décadas e séculos de interação direta, noção inequívoca de que a natureza antecede e fundamenta o gênero humano, é transformada por ele e acaba transformando-o em um processo dialético. 


\title{
0 trabalho na pesca
}

O trabalho é definido por Marx (2013, p. 255) como:

\begin{abstract}
[...] Antes de tudo, um processo entre o homem e a natureza, processo este em que o homem, por sua própria ação, medeia, regula e controla seu metabolismo com a natureza. [...] A fim de se apropriar da matéria natural de uma forma útil para sua própria vida, ele põe em movimento as forças naturais pertencentes a sua corporeidade [...] agindo sobre a natureza externa e modificando-a por meio desse movimento, ele modifica, ao mesmo tempo, sua própria natureza.
\end{abstract}

Por meio de suas forças intrínsecas, os seres humanos são capazes de, ao retirar da natureza seu sustento, transformá-la, e esta transformação acaba incidindo sobre a própria humanidade. Este caráter ontológico do trabalho pode ser exemplificado pelos impactos sobre a pesca na lagoa advindos da implementação da Lei da Pesca e o surto desenvolvimentista da atividade pesqueira na região. A dinâmica particular da pesca na região do estuário e costa oceânica, devido à limitada capacidade técnica, até a década de 1970 tendia a limitar-se a abordagens periféricas dos cardumes, utilizando principalmente os sentidos e a força dos corpos humanos para realizar as pescarias. As lembranças desse período, como podem ser observadas em XXX (2011), são matizadas pelo saudosismo em contraposição à escassez atual, produto do desenvolvimento da capacidade de predação das unidades produtoras, sejam as pequenas parelhas, sejam as indústrias frigoríficas que se utilizaram amplamente de subsídios e isenções para se instalarem.

A atividade produtiva pesqueira impulsionada pelos recursos da Lei da Pesca representou um incremento imediato à renda e à industrialização no município de São José do Norte, vendo a chegada de duas indústrias frigoríficas em um primeiro momento Frigoria e Confrio - e, posteriormente, a abertura do frigorífico Moura que, juntas, chegaram a empregar 1.200 pessoas (XXX, 2011, p. 69). Esse breve período de progresso econômico resultou no colapso da lagoa, visto que o superdimensionamento da captura e industrialização do pescado, dada a desconsideração sobre os limites naturais de renovação dos cardumes, teve por principal consequência o comprometimento da realização da pesca por décadas até hoje. Por meio do trabalho, os operários e pescadores transforaram o meio e se transformaram no processo.

Evidentemente, esta autotransformação do gênero humano não se dá apenas por meio de consequências negativas do trabalho, mas na própria formação do trabalhador, que vinha se constituindo no momento mesmo em que produzia. Nesse sentido, pelo trabalho, o trabalhador produz e se produz, atuando junto à natureza para se realizar enquanto sujeito.

O sentido do trabalho para os pescadores artesanais se distancia da concepção do trabalho na sociedade capitalista, o trabalho abstrato, que converte o mundo humano "[...] em um mundo penoso, alienante, aprisionado e unilateralizado" (ANTUNES, 2018, p. 25). Embora Mané destaque que a pesca seja uma profissão "ralada", que "judia", e que seja "muito perigosa", ainda assim ela traz satisfação a seus profissionais. 


\section{Trabalho concreto}

Seu Lica demonstrou, desde cedo, uma particular aptidão para o trabalho na pesca. De doze para treze anos ele abandonou a educação formal e empregou-se como proeiro no caíco Rio Tietê, e aos dezesseis anos já havia escalado ao posto de patrão da parelha.

Eu comecei costurando rede pro meu cunhado. Comecei como proeiro. Em seguida, não chegou quase nem um ano, o que era meu patrão, ele foi pra proeiro e eu fui pra patrão. Isso aconteceu. Ele até morreu há pouco tempo, ano passado [...] e ele era patrão do caíco, um caíco que chamava Rio Tietê. Porque a parelha que nós trabalhava do falecido meu cunhado ali, tudo tinha nome. Até quem pintava os letreiro, eles pintavam o zarcão, o verde e o branco, uma listra verde e uma bandeira brasileira na proa, ou uma estrela verde e amarela.

À época da entrada de seu Lica na atividade pesqueira, em meados da década de 1950, boa parte das atividades da parelha era realizada manualmente, com a produção e costura das redes, a construção dos galpões, a produção de embarcações. A primeira atividade de seu Lica numa parelha de pesca, a feitura e remendo de redes, se fazia a mão:

[...] naquela época só se fazia a mão, era fiozinho de linha Ursa, que chamava o nome, uns novelinho de fio que o cara comprava naqueles pacote. Se prendia. Uma rede dava um quilo, mais ou menos, uma rede de umas trinta braça por aí. Pô, era um fio bom pra pescaria.

A polivalência do pescador artesanal à época de seu Lica representa uma tendência à compreensão integral, não parcializada, do trabalho na pesca. Não basta a existência de um emprego ou um empregado, é necessário compreender a pesca como um processo amplo e desempenhar tarefas neste âmbito amplo da profissão: seja o remendo da rede, a pintura da embarcação, ou a liderança no lance, o sujeito que trabalha na pesca deve ser polivalente, ocupar os vários espaços que a atividade oferece.

Iniciam por aqui as distinções que afastam o trabalho na pesca artesanal e o trabalho na sociedade capitalista, voltada integralmente para o trabalho abstrato. A disposição que o pescador deve ter para fazer um trabalho que é um trabalho de vida independe de jornada de trabalho e carga horária. É um trabalho sazonal, adaptado aos ritmos da natureza, em seu caráter harmônico, mas sempre lutando para sobreviver, em seu caráter conflituoso. Não se utiliza a exploração do sobretrabalho para a extração de um mais-valor entre os pescadores, além de ser um trabalho que traz satisfação.

Ao descrever a prática profissional dentro da parelha, seu Lica aponta:

Comigo trabalhavam duas pessoas, e eu três. Botava sempre dois proeiro. Às vezes botava três, e eu quatro. E matava um bocado de peixe. Trabalhava noite e dia, gostava de trabalhar. Sempre, sempre. Só descansava um pouco, almoçava, jantava e ia pro mar. Tirava um descanso, chamava os proeiro: "Vamo sair", "Ué, mas...", "Vamo pro mar", e lá ia. Dava dois, três lance, e vinha embora pra terra.

Para além da necessidade de provir o sustento, a satisfação obtida na atividade pesqueira aponta para a afirmação através do trabalho, tanto que os filhos adolescentes dos pescadores artesanais aproveitavam esses breves momentos de folga dos pais para se iniciar na vida embarcada, como diz Ricardo, pescador artesanal que teve atuação como 
servidor público e como operário em estaleiro de produção de plataformas de exploração de petróleo:

[...] E a gente ia pro mar e às vezes chegava na hora do meio dia, que o pai queria descansar alguma coisa, e a gente tava ali influindo: "O pai vai dormir agora na hora do meio dia, vamo pro mar, vamo pro mar", e o pai disse: "Não, já não é hora de ir pro mar". A gente era muito influído, e começou assim, desde pequeno.

Vê-se que o desejo dos jovens em participar das atividades produtivas dos pais, além de uma necessidade, pois representava um acréscimo de braços para a realização do trabalho, trazia a esses jovens o sentimento de pertencimento a um grupo que extravasava os limites da família nuclear. O trabalho na pesca criava o sentimento de comunidade, de existência para além do indivíduo, evidente na formação comunitária das parelhas, nas quais se contava com irmãos, cunhados e primos.

A parelha de pesca, espaço eminentemente masculino, passou por algumas transformações a partir da emigração dos catarinas, pescadores que deixaram o estado de Santa Catarina durante as décadas de 1940 a 1960, quando as mulheres tiveram de ocupar um maior destaque na prática da pesca propriamente dita, como aponta Mariza:

\begin{abstract}
Aprendi a pescar depois de casada, porque, bem antes, era uma época em que poucas mulheres iam pra parelhas grande, como meu pai sempre teve, parelha de pesca no oceano e parelhas aqui eram grandes, então ele colocava muita gente pra trabalhar, muitos homens, então as mulheres, filhas mulheres nem chegavam perto. Mas como começou depois essa diminuição [...] e começou a parar de vir tanta gente pra cá trabalhar, que vinha muito de Santa Catarina.
\end{abstract}

Os catarinas, que buscavam até meados da década de 1950 e 1960 a Lagoa dos Patos para se empregar, se tornando o símbolo do trabalho precarizado, oferecem um interessante contraponto a esta noção de trabalho integral e satisfatório que até agora se desenha para a pesca artesanal, pois se trata de sujeitos que, por falta de oportunidades em seu estado, tiveram de empreender um movimento migratório não só para o sul do país, mas para diversas partes do litoral brasileiro (DIEGUES, 1983, p. 124). Nesse contexto os catarinas representam uma realidade de despossessão e desterritorialização, remediada com os investimentos na industrialização da pesca em litoral catarinense.

A comunidade pesqueira, conforme coloca Mariza, passou a integrar as mulheres de forma mais direta no processo produtivo, ampliando a reserva de força de trabalho disponível. Com a desestruturação das grandes parelhas e a reconfiguração das unidades produtivas, a inserção das mulheres acabou por representar uma ruptura na eminência masculina nas parelhas.

[...] A gente começou a pensar em ajudar o marido, ajudar os pais a estar indo pra pesca, a estar aprendendo alguma coisa no sentido de agregar valor ao pescado pra poder sustentar a família. [...] Já quando a gente tava fazendo aquele trabalho da pastoral [Conselho Pastoral dos Pescadores]... alertando e mostrando que existiam formas de que a gente podia agregar valor e viver com menos pescado, e de formas como também a mulher poderia ter um papel importante, porque não só aquela que ia pescar, mas também aquela que fica em terra e que cuida de apetrechos, de remendar rede, além de beneficiar o pescado, a filetagem, o descasque do camarão, pra agregar valor. 
Longe de representar uma igualdade de gênero, a participação do trabalho feminino na pesca traz à tona o papel da mulher pescadora na atividade no estuário. Ao realizar a entrevista com seu Lica se teve a oportunidade de observar o trabalho de dona Vera, sua viúva, junto de suas companheiras descascando o camarão que havia sido capturado pelos pescadores na noite anterior. $O$ valor agregado por essa atividade representa um acréscimo de até cem por cento ao valor do camarão sujo, e a conquista de um espaço essencial para as mulheres pescadoras e para as comunidades pesqueiras.

Além disso, o trabalho feminino na pesca, nos termos apresentados por Mariza, vai ao encontro da priorização da qualidade apontada por Toco anteriormente. Com o incremento de valor, se torna possível exercer uma menor pressão sobre os cardumes, preservando a piscosidade na lagoa que se encontra em queda.

Em síntese, os pescadores artesanais do estuário da Lagoa dos Patos executam um processo de mediação, regulação e controle em seu metabolismo com a natureza caracterizado, entre outros fatores, a) pelo aspecto polivalente da atividade, devendo compreender a totalidade da prática profissional, desde a produção dos apetrechos até as atividades de refino do pescado, como a filetagem e o descasque, passando pela compreensão da dinâmica da natureza, o que em certa medida unifica trabalho manual e trabalho intelectual; b) pela emergente participação das mulheres em diferentes estágios da produção, trazendo para a pesca a preocupação com o aumento da qualidade e a diminuição da quantidade de capturas; c) pelo caráter comunitário da atividade, contando com a convergência da família estendida na realização das tarefas da pesca; e d) pela satisfação advinda da prática pesqueira, fator inseparável de sua concepção da natureza, bem como da inexistência de uma exploração do sobretrabalho que seria apropriado pelo proprietário dos meios de produção, valorizando o tempo livre dos pescadores.

\section{Considerações finais}

As duas concepções fundamentais para a articulação de uma Educação Ambiental que esteja envolvida com a transformação social indubitavelmente são natureza e trabalho: a primeira, considerada o corpo inorgânico do homem, é o ambiente no qual a vida humana e não-humana se dá; o segundo, forma pela qual o ser humano medeia, regula e controla seu metabolismo com a natureza. Deixando de lado uma postura utilitarista, pragmática e alienante de natureza e trabalho, a Educação Ambiental precisa, para pôr em curso seus ideais de construção de uma forma alternativa de sociabilidade que não se fundamente na exploração indiscriminada, ressignificar estas duas concepções.

Para a práxis transformadora, as noções de natureza, e as relações que se estabelecem com ela, e de trabalho advindas de grupos tradicionais, como o dos pescadores artesanais, são de fundamental importância, e torna-se uma prerrogativa para os educadores ambientais que estejam envolvidos com a reflexão e ação políticas e pedagógicas inerentes à Educação Ambiental dispor de subsídios para construir sua atuação profissional e militante. $O$ processo de crítica e conscientização, transformação e emancipação 
necessitam de subsídios com os quais possam embasar sua teoria e sua prática, reunindo as condições materiais para encaminhar a construção de alternativas à sociedade capitalista industrial moderna.

Cabe, portanto, ao educador ambiental, realizar um movimento de aproximação aos grupos e comunidades tradicionais para, desta forma, subsidiar sua práxis em Educação Ambiental. Reconhecendo estas formas alternativas de conceber a natureza e o trabalho, 0 educador ambiental se capacita a construir junto às comunidades formas pelas quais possa estar realizando uma crítica subsidiada à forma pela qual as coisas estão sendo postas na sociedade capitalista, construindo, pela via dos grupos tradicionais, alternativas viáveis rumo a uma sociedade socialmente justa e ambientalmente sustentável. A negação ao que se tem por natureza e trabalho na sociedade contemporânea e a necessidade de substituição dessas concepções, considerando que as duas resumem as duas maiores riquezas da humanidade e têm a potência de constituir uma relação teoria-prática dotada dos elementos fundamentais da crítica para uma práxis transformadora, constituem um passo fundamental que o educador ambiental precisa dar rumo à construção desse modelo alternativo de produção e reprodução da vida.

\section{Referências}

ANTUNES, Ricardo. 0 privilégio da servidão: o novo proletariado de serviços na era digital. São Paulo: Boitempo, 2018. 325 p.

BENJAMIN, Walter. Charles Baudelaire: um lírico no auge do capitalismo. Tradução de José Carlos Martins Barbosa e Hemerson Alves Baptista. 3.ed. São Paulo: Brasiliense,1994. 271 p.

BRAVO, Maicon Dourado. Na maré das lembranças: memória, pesca artesanal, globalização e educação ambiental no contexto da Laguna dos Patos. 2011. 103 f. (Mestrado em Educação Ambiental) - Programa de Pós-Graduação em Educação Ambiental, Universidade Federal do Rio Grande, Rio Grande, 2011.

DIEGUES, Antônio Carlos Sant'Ana. 0 mito moderno da natureza intocada. 6.ed. São Paulo: Hucitec/Nupaug, 2008. 198 p.

DIEGUES, Antônio Carlos Sant'Ana. Pescadores, camponeses e trabalhadores do mar. São Paulo: Ática, 1983. 287 p.

DUARTE, Rodrigo A. de Paiva. Marx e a natureza em O Capital. 2.ed. São Paulo: Loyola, 1995. $110 \mathrm{p}$.

ENGELS, Friedrich. A dialética da natureza. 3.ed. Rio de Janeiro: Paz e Terra, 1979. 240 p.

FOSTER, John Bellamy. A ecologia de Marx. Tradução de Maria Teresa Machado. 3.ed. Rio de Janeiro: Civilização Brasileira, 2011. 418 p. 
GAÚCHAZH. AMBIENTE. Lama reaparece na beira da Praia do Cassino e reacende discussão sobre dragagem. Porto Alegre: 11/12/2018. Disponível em https://gauchazh.clicrbs.com.br/ambiente/noticia/2018/12/lama-reaparece-na-beira-dapraia-do-cassino-e-reacende-discussao-sobre-dragagemc.jpimsn210kcb01rxkmibmad0.html, acesso em 30/04/2020.

LOUREIRO, Carlos Frederico Bernardo. Sustentabilidade e educação: um olhar da ecologia política. São Paulo: Cortez, 2012a. 128 p.

LOUREIRO, Carlos Frederico Bernardo. Teoria social e questão ambiental: pressupostos para uma práxis crítica em educação ambiental. In: LOUREIRO, Carlos Frederico Bernardo; LAYRARGUES, Philippe Pomier; CASTRO, Ronaldo Souza de (orgs.). Sociedade e meio ambiente: a educação ambiental em debates. 7.ed. São Paulo: Cortez, 2012b. p. 17-54.

MARX, Karl. Crítica ao programa de Gotha. Tradução de Rubens Enderle. São Paulo: Boitempo, 2012. 140 p.

MARX, Karl. Manuscritos econômico-filosóficos. Tradução de Jesus Ranieri. São Paulo: Boitempo, 2010. 190 p.

MARX, Karl. O capital: crítica da economia política: Livro I: o processo de produção do capital. Tradução de Rubens Enderle. São Paulo: Boitempo, 2013. 894 p.

\section{Informações sobre os autores:}

\section{Maicon Dourado Bravo}

Mestre em Educação Ambiental pela Universidade Federal do Rio Grande (FURG). Atua como Professor na Secretaria Municipal de Educação de Pelotas/RS e na Secretaria de Estado de Educação do Rio Grande do Sul.

ORCID iD: https://orcid.org/0000-0002-9757-3635

E-mail: maicondbravo@gmail.com

\section{José Vicente de Freitas}

Doutor em História e Sociedade pela Universidade Estadual Paulista Júlio de Mesquita Filho (UNESP). Atua como Professor no Instituto de Ciências Humanas e Informação (ICHI) da Universidade Federal de Rio Grande (FURG), onde integra o quadro docente do Programa de Pós-Graduação em Educação Ambiental (PPGEA). Integra o Conselho Consultivo da Revista Ambiente e Educação (PPGEA/FURG) e da Revista Eletrônica do Mestrado em Educação Ambiental (PPGEA/FURG). É membro do Conselho Editorial da Revista Brasileira de Educação Ambiental. Consultor ad hoc da UNESCO, PNUD e OTCA; facilitador, no Brasil, e revisor pedagógico, do Curso Piloto da Unesco para professores sobre Educação em 
Mudança Climática e Desenvolvimento Sustentável; disseminador dos Objetivos do Desenvolvimento sustentável no Brasil.

ORCID iD: https://orcid.org/0000-0001-7121-9921

E-mail:jvfreitas45@gmail.com

Submetido em: 25/09/2019

Aprovado em: $\quad 29 / 12 / 2019$

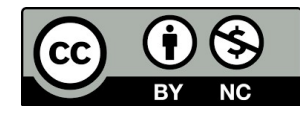

